\title{
Critical Determinants for Mobile Commerce Adoption in Vietnamese SMEs: A Preliminary Study
}

\author{
Ngoc Tuan Chau ${ }^{1,2}$ \\ ${ }^{1}$ School of Business IT \& Logistics \\ RMIT University \\ Melbourne, Australia \\ Email: tuan.chau@rmit.edu.au \\ ${ }^{2}$ University of Economics, The University of Danang \\ Danang city, Vietnam
}

\author{
Hepu Deng \\ School of Business IT \& Logistics \\ RMIT University \\ Melbourne, Australia \\ Email: hepu.deng@rmit.edu.au
}

\begin{abstract}
The critical determinants for e-commerce, e-business, and other enterprise information systems adoption in SMEs have been well-documented. The critical determinants for $\mathrm{m}$-commerce adoption in SMEs, however, are still limited, especially in SMEs in developing countries. This paper develops a measurement instrument for investigating the critical determinants of $\mathrm{m}$-commerce adoption in Vietnamese SMEs. A preliminary study is conducted for confirming the reliability and validity of the instrument based on the data collected from 172 managers of Vietnamese SMEs using an online survey. The Cronbach's alpha and the composite reliability values of the proposed variables strongly support their reliability. The results of the exploratory factor analysis confirm constructs' discriminant validity. The average variance extracted values confirm constructs' convergent validity. This study contributes to the identification of the critical determinants for m-commerce adoption in SMEs. It provides a new conceptual framework for assessing the critical determinants for $\mathrm{m}$-commerce adoption in SMEs in developing countries.
\end{abstract}

Keywords Mobile commerce, critical determinants, adoption, SMEs, Vietnam. 


\section{Introduction}

M-commerce is about buying and selling of goods and services through wireless handheld devices such as cellular phones and personal digital assistants (Smith 2006; Njenga, Litondo and Omwansa 2016). It provides organizations with many benefits including improving productivity, increasing customer satisfaction, and lowering operational costs (Varshney and Vetter 2004). As a result, mcommerce is becoming a cost-effective way for businesses to promote their products and services online (Mallat and Tuunainen 2008; Alfahl, Sanzogni and Houghton 2012; Njenga, Litondo and Omwansa 2016).

The popularity of m-commerce leads to its wide adoption in the world. A careful investigation of such adoption reveals that there is a huge difference in the adoption between the developed country and the developing country. While m-commerce has a high level of adoption in developed countries (Mbogo 2010), it has not been popularly adopted in developing countries (Chong 2013; Nafea and Younas 2014).

SMEs can be defined differently across countries with respect to the number of employees, the turnover, and the ownership structure (Poon 2002; Ayyagari, Beck and Kunt 2007). In Vietnam, SMEs are an independent business with the average number of permanent workers not exceeding 300 (Insides 2011). SMEs play an important role in the Vietnamese economy. They account for approximately $98 \%$ of the enterprises, contributing more than $40 \%$ of national gross domestic products and $30 \%$ of total export, and creating more than 500.000 workplaces annually (General Statistics Office of Vietnam 2016).

SMEs are a distinct group of organizations with their specific characteristics (Poon 2002; Ayyagari, Beck and Kunt 2007). These characteristics make them more flexible in adopting technological innovations. The flattened structure of SMEs enables much faster decision making. However, the lack of ICT skills (Barry and Milner 2002; OEDC 2004), the lack of financial resources (Tetteh and Burn 2001; Hamdan et al. 2016), and the dependence on business partners (Stockdale and Standing 2004) often pose numerous challenges for SMEs in their adoption of technological innovations.

The tremendous benefits of $\mathrm{m}$-commerce for SMEs have not been fully utilized in developing countries (Nafea and Younas 2014). In Vietnam, for example, there are about 20\% of SMEs that have websites for promoting their business. About $70 \%$ of these websites are difficult to access by mobile devices (VECITA 2017). This is because the adoption of m-commerce is a complex process (Stoica, Miller and Stotlar 2005). There are many factors such as individual attributes (Njenga, Litondo and Omwansa 2016), technological, organizational, and environmental aspects (Alfahl, Sanzogni and Houghton 2012; Njenga, Litondo and Omwansa 2016), and trust (Rahman 2013) which directly affect the adoption of organizational $\mathrm{m}$-commerce. To have a successful adoption, an investigation of the critical determinants for m-commerce adoption in Vietnamese SMEs is significant. This paper conducts a preliminary study on the critical determinants for m-commerce adoption in Vietnamese SMEs by answering the following research question:

Which critical determinants can be included for investigating the critical determinants for $m$ commerce adoption in Vietnamese SMEs?

\section{Literature Review}

The lack of research in identifying the critical determinants for m-commerce adoption in organizations has attracted much attention in existing literature. There are several important attempts at developing various measurement models from different perspectives for identifying the critical determinants of adopting $\mathrm{m}$-commerce in organizations. These studies can be categorized into the conceptualization of $\mathrm{m}$-commerce adoption and the empirical validation of such conceptualization.

The conceptualization of m-commerce adoption focuses on the proposition of various conceptual frameworks for better understanding the adoption of $\mathrm{m}$-commerce in organizations. Stoica, Miller and Stotlar (2005), for example, conceptualize a comprehensive framework consisting of organizational structure, business strategy, organizational culture, and environment for m-commerce adoption. Alfahl, Sanzogni and Houghton (2012) develop a framework related to technological factors, environmental \& organizational factors, and policy \& legal environment factors for $\mathrm{m}$-commerce adoption. Njenga, Litondo and Omwansa (2016) present an integrated framework for m-commerce adoption consisting of organizational attributes and individual attributes. Alqatan et al. (2017) present a conceptual framework consisting of perceived usefulness, perceived ease of use, and the fit between mobile technologies and tasks for investigating the acceptance of m-commerce in tourism SMEs. 
These studies propose various conceptual models for organizational m-commerce adoption. They, however, lack empirical evidences for the generalizability of the findings for the organizational mcommerce adoption.

Several studies empirically investigate the critical determinants for the adoption of m-commerce in organizations. Such studies employ various theories such as the technology acceptance model (TAM), the diffusion of innovation theory (DOI), and the technology-organization-environment (TOE) framework for investigating the adoption of $\mathrm{m}$-commerce in organizations, leading to the identification of different critical determinants. The use of TAM, for example, assumes that the intention of an organization in adopting m-commerce is influenced by the perceived usefulness and the perceived ease of use. Snowden et al. (2006), for example, extend TAM for investigating the critical factors affecting the adoption of mobile technologies, leading to the identification of the critical determinants including the usefulness and ease of use of mobile technologies, the technology complexity, individual differences, facilitating conditions, social influences, and wireless trust environment. Shih et al. (2010) extend TAM to study m-commerce adoption in real estate organizations. The results show that perceived usefulness, perceived ease of use, and the tool experience are critical for the adoption of m-commerce. Mashagba, Mashagba and Nassar (2013) extend TAM for investigating the technological factors affecting m-commerce adoption in Jordan, leading to the confirmation of the critical determinants including perceived usefulness, perceived ease of use, IT trust, level of e-commerce adoption, security, and IT infrastructure.

The use of DOI in organizational m-commerce adoption studies assumes that the adoption of $\mathrm{m}$ commerce in organizations is determined by relative advantage, compatibility, complexity, trialability, and complexity. Al-Qirim (2006), for example, employs DOI for investigating the adoption of mobile technologies in SMEs in New Zealand, leading to the confirmation of five critical determinants including relative advantage, compatibility, complexity, cost, and support from technology vendors.

The adoption of TOE for exploring the m-commerce adoption in organizations states that there are three main aspects of an organization that influence the adoption of m-commerce, namely technology, organization, and environment. Doolin and Ali (2008), for example, employ TOE for investigating the critical determinants for the adoption of mobile technologies in business in New Zealand, leading to the confirmation of the critical determinants including relative advantage, compatibility, top management support, information intensity, the degree of organizational readiness, competitive intensity and partner influence. Jain et al. (2011) employ TOE to explore the factors favouring mcommerce adoption in Indian micro, small and medium-sized enterprises. Their empirical results indicate that IS infrastructure, relative advantage, complexity, trialability, firm size, financial commitment, IS expertise, trading partner readiness, external IS support are the critical determinants for the adoption of m-commerce. Lu et al. (2015) adopt TOE for evaluating the critical factors affecting the decision to implement m-commerce in SMEs in Taiwan, leading to the identification of nine critical determinants including data security, network reliability, technology complexity, top management emphasis, employees' IS knowledge, firm size, competitive pressure, partner support, and regulatory support. Martin and Jimenez (2015) employ TOE to investigate the adoption of mcommerce in Spanish firms, leading to the identification of various critical determinants including motivation, perceived benefits, managers' and employees' support, impediments to implement, perceived customer value, competitive pressure, and the propensity to innovation and ICT.

An integration of several theories is commonly used for better understanding m-commerce adoption in organizations. Martin, Catalan and Jeronimo (2012), for example, integrate TOE and a relational context (Dyer and Singh 1998) to identify the critical factors for the adoption of m-commerce. Picoto, Belanger and Palma-dos-Reis (2014) combine TOE with DOI and the resource-based theory to investigate the use of mobile business. Alrawabdeh (2014) combines TAM with DOI and the theory of reasoned action to investigate the environmental factors affecting $\mathrm{m}$-commerce adoption in telecommunication firms in Jordan. Otieno and Kahonge (2014) integrate TOE with DOI for investigating the adoption of mobile payment in Kenyan SMEs. Grandhi and Wibowo (2016) integrate TAM with DOI to examine the organizational factors affecting m-commerce adoption in Organizations in North America. Amegbe, Hanu and Nuwasiima (2017) combine TAM and DOI for investigating the use of mobile money and m-commerce. Alfahl, Houghton and Sanzogni (2017) integrated TOE with TAM, DOI, TRA, and TPB for exploring m-commerce adoption in Saudi organizations. These studies employ various theories as a theoretical basis for better understanding $\mathrm{m}$-commerce adoption, leading to the confirmation of different determinants for $\mathrm{m}$-commerce adoption in organizations.

The models above, however, have some limitations for adequately identifying the critical determinants for m-commerce adoption in SMEs in developing countries. First, they do not have a general 
agreement on the critical determinants for m-commerce adoption in organizations. Second, they lack consideration of the unique characteristics of SMEs in the adoption of m-commerce. Furthermore, they have not considered the characteristics of developing countries in the adoption of new technologies. As a result, there is a necessity to develop and empirically validate a comprehensive measurement model for identifying the critical determinants for $\mathrm{m}$-commerce adoption in Vietnamese SMEs - an example of SMEs in the context of developing countries.

\section{A Conceptual Framework}

The analysis of existing studies above shows that DOI and TOE are the dominant theories for investigating the critical determinants for the adoption of $\mathrm{m}$-commerce in organizations. DOI is a process-based framework for explaining how, why, and at what rate the technology is adopted (Rogers 2010). It has become the most influential theory in adoption studies. As a result, the DOI theory is widely used as a theoretical basis in many empirical studies for identifying the critical determinants of technology adoption in SMEs (Seyal, Rahman and Mohammad 2007; Alam et al. 2008).

TOE is an organization-level theory of technology adoption that describes how the firm context influences the adoption of technological innovations (Baker 2012). It provides a solid theoretical basis for identifying the critical determinants of technology adoption in organizations (Oliveira and Martins 2010). As a result, it is widely employed in many adoption studies (Duan, Deng and Corbit 2010, 2012; Huy et al. 2012; Imre 2016).

Figure. 1 presents a conceptual framework for investigating the critical determinants of m-commerce adoption in Vietnamese SMEs. Such a framework integrates two most popular theories in technology adoption in organizations including DOI and TOE. This is because DOI and TOE are the most suitable theories for investigating the critical determinants for the adoption of m-commerce in organizations.

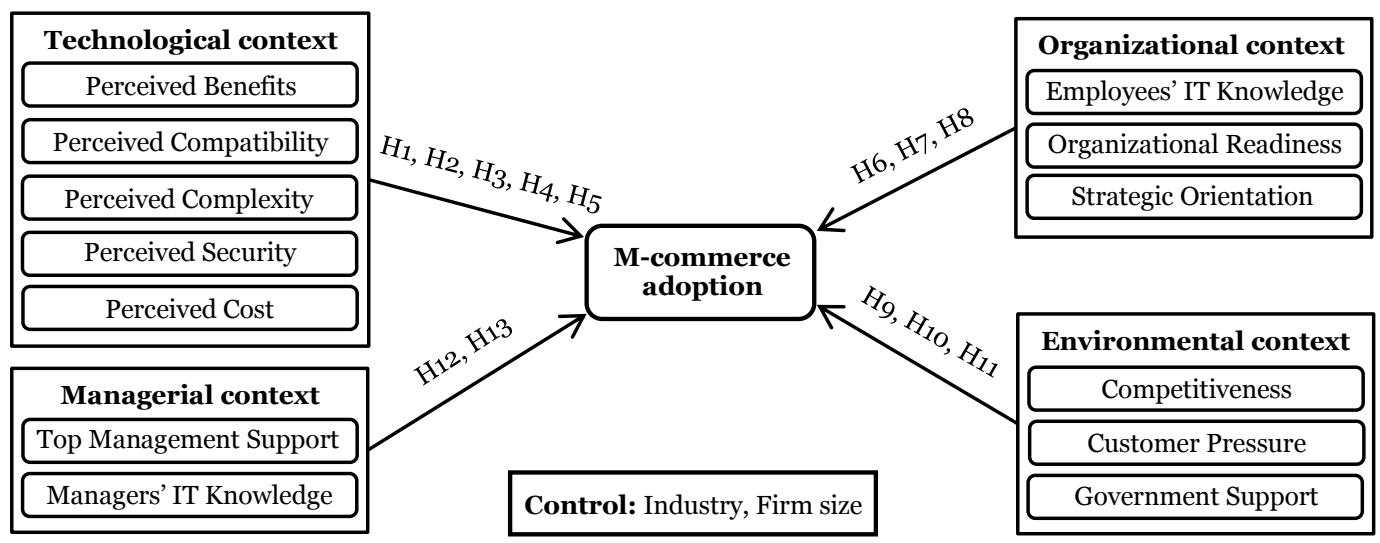

Figure 1: The conceptual framework

The proposed framework conceptualizes that factors affecting the adoption of $\mathrm{m}$-commerce can be categorized into technological context, organizational context, environmental context, and managerial context. The perceived cost and perceived security are included for extending DOI, and the managerial context is added for extending TOE for having a comprehensive framework for a more robust explanation on the adoption of m-commerce in SMEs in the context of Vietnam.

The technological context is related to the characteristics of the technology (Rogers 2010). It represents the technologies available for the adoption of m-commerce (Lu et al. 2015). A review of the related literature shows that perceived benefits, perceived compatibility, and perceived complexity are the most important factors affecting m-commerce adoption in organizations. Additionally, the perceived cost and perceived security are included in the technological context for extending DOI for the context of Vietnamese SMEs. As a result, five following hypotheses are proposed:

H1: The perceived benefits are critical for the decision to adopt m-commerce

H2: The perceived compatibility is critical for the decision to adopt m-commerce

H3: The perceived complexity is critical for the decision to adopt m-commerce

H4: The perceived security is critical for the decision to adopt m-commerce 
H5: The perceived cost is critical for the decision to adopt m-commerce

The organizational context is related to the characteristics of an organization in the adoption of innovation. It represents internal factors for the adoption of innovations (Lippert and Govindarajulu 2006). A review of the related literature shows that the most important organizational factors are employees' IT knowledge, organizational readiness, and strategic orientation. As a result, three following hypotheses are proposed:

H6: Employees' IT knowledge is critical for the decision to adopt m-commerce

H7: The organizational readiness is critical for the decision to adopt m-commerce

H8: A firm' strategic orientation is critical for the decision to adopt m-commerce

The environmental context constitutes the arena in which adopting organizations conduct their business (Depietro, Wiarda and Fleischer 1990). The literature review leads to the identification of several environmental factors including competitive pressure, customer pressure, and government support for m-commerce adoption (Vaithianathan 2010). As a result, three hypotheses are proposed:

H9: The perception of competitive pressure is critical for the decision to adopt m-commerce

H1O: The perception of customer pressure is critical for the decision to adopt m-commerce

H11: The perception of government support is critical for the decision to adopt m-commerce

The managerial context is related to the characteristics of the manager of SMEs in technology adoption. Such characteristics are critical for adopting innovations. Rogers (2010) argues that innovation adoption is significantly correlated with the innovation-decision process, in particular, the attitude of managers. These lead to the proposition of the two following hypotheses:

H12: Top management support is critical for the decision to adopt m-commerce

H13: Managers' IT knowledge is critical for the decision to adopt m-commerce

\section{Research Method}

A quantitative study was conducted using an online survey with a questionnaire. The target population is SMEs in Vietnam. The sampling frame was obtained from the Vietnam Association of Small and Medium Enterprises (VINASME) website using the probability sampling method. The sampling frame is the owners and managers of Vietnamese SMEs.

The questionnaire includes closed-ended questions and consists of three parts: the demographic questions about the SMEs and respondents, questions about the current patterns of the adoption of $\mathrm{m}$-commerce in Vietnamese SMEs, and questions for assessing the determinants for $\mathrm{m}$-commerce adoption in Vietnamese SMEs. The questionnaire was delivered online with the support from VINASME from April 2018 to June 2018. One-hundred and seventy-eight surveys were received and processed with data screening. This process excludes six surveys with many unfinished questions, resulting in one-hundred and seventy-two valid surveys for the statistical analysis using SPSS 25.o.

\section{Preliminary Data Analysis}

\subsection{Respondent Profile}

Table 1 presents a summary of the demographic data. With respect to the location of SMEs, $44.2 \%$ of SMEs are in North Vietnam, $40.1 \%$ of SMEs are in the Central and Highland Vietnam, and $15.7 \%$ of SMEs are located in South Vietnam. Regarding the duration of business, most SMEs have been running their businesses for more than 15 years (47.7\%), 21.5\% of SMEs have been running their businesses for less than 5 years, $18 \%$ between 5 to 10 years, and $12.8 \%$ between 10 to 15 years. With respect to the size of the enterprise, 26.2\% of SMEs are very small enterprises with less than 10 employees, $56.3 \%$ of SMEs are small enterprises with 10 to 200 employees, and $17.5 \%$ of SMEs are medium enterprises with 201 to 300 employees. Regarding the industry, most of the SMEs are from trading and services industries with $22.1 \%$ and $21.5 \%$ respectively, followed by the enterprises in the construction industry (15.1\%). There are $10.5 \%$ of SMEs in the manufacturing industry and $10.5 \%$ of SMEs in finance, insurance, and real estate. The rest are SMEs from other sectors such as transportation, information, media and communication, medicine and healthcare. Among these participations, $24.4 \%$ of SMEs have adopted m-commerce, and $75.6 \%$ of SMEs have not adopted this type of business model. 


\begin{tabular}{|c|c|c|c|c|c|c|c|}
\hline Category & Description & Frequency & Percent & Category & Description & Frequency & Percent \\
\hline \multirow{3}{*}{$\begin{array}{l}\text { Location } \\
\text { of SMEs }\end{array}$} & North Vietnam & 76 & $44.2 \%$ & \multirow{4}{*}{$\begin{array}{l}\text { Duration of } \\
\text { business }\end{array}$} & $<5$ years & 37 & $21.5 \%$ \\
\hline & Central and Highland & 69 & $40.1 \%$ & & $5-10$ years & 31 & $18.0 \%$ \\
\hline & South Vietnam & 27 & $15.7 \%$ & & $10-15$ years & 22 & $12.8 \%$ \\
\hline \multirow{9}{*}{ Industry } & Construction & 26 & $15.1 \%$ & & $>15$ years & 82 & $47.7 \%$ \\
\hline & Trading & 38 & $22.1 \%$ & \multirow{6}{*}{$\begin{array}{l}\text { Size (No. of } \\
\text { employees) }\end{array}$} & $<10$ & 45 & $26.2 \%$ \\
\hline & Services & 37 & $21.5 \%$ & & $10-50$ & 57 & $33.1 \%$ \\
\hline & Manufacturing & 18 & $10.5 \%$ & & $51-100$ & 20 & $11.6 \%$ \\
\hline & Healthcare & 10 & $5.8 \%$ & & $101-200$ & 20 & $11.6 \%$ \\
\hline & Transportation & 3 & $1.7 \%$ & & $201-300$ & 30 & $17.5 \%$ \\
\hline & ICT & 9 & $5.2 \%$ & & $>300$ & 0 & $0 \%$ \\
\hline & Finance \& insurance & 18 & $10.5 \%$ & \multirow{2}{*}{ Adoption } & Adopter & 42 & $24.4 \%$ \\
\hline & Others & 13 & $7.6 \%$ & & Non-adopter & 130 & $75.6 \%$ \\
\hline
\end{tabular}

Table 1. Demographic characteristic of the SMEs

\subsection{Reliability Analysis}

A reliability analysis was conducted to assess the stability of the measurement instrument. As the constructs proposed in the framework were measured by multiple items, the internal reliability must be calculated to confirm their internal consistency (Creswell 2012). Thirteen proposed independent variables were estimated for internal consistency by calculating the Cronbach's alpha as shown in Table 2. The results indicate that the average of the Cronbach's alpha value is ranged from 0.836 for perceived complexity to 0.945 for employees' IT knowledge. Out of the thirteen variables, six variables have excellent reliability with the Cronbach's alpha value from 0.9, and seven variables have good reliability with the Cronbach's alpha value between 0.8 and 0.9 . These results indicate that the internal consistency of the instrument is acceptable and reliable.

\begin{tabular}{|c|c|c|c|c|}
\hline Dimensions & Variables & N.o of Items & Cronbach's Alpha & Reliability Strength \\
\hline \multirow{5}{*}{$\begin{array}{l}\text { Technological } \\
\text { factors }\end{array}$} & Perceived Benefits & 8 & 0.912 & Excellent \\
\hline & Perceived Compatibility & 6 & 0.888 & Good \\
\hline & Perceived Complexity & 3 & 0.836 & Good \\
\hline & Perceived Security & 3 & 0.848 & Good \\
\hline & Perceived Cost & 3 & 0.891 & Good \\
\hline \multirow{3}{*}{$\begin{array}{l}\text { Organizational } \\
\text { factors }\end{array}$} & Employees' IT knowledge & 3 & 0.945 & Excellent \\
\hline & Organizational readiness & 3 & 0.839 & Good \\
\hline & Strategic orientation & 3 & 0.850 & Good \\
\hline \multirow{3}{*}{$\begin{array}{l}\text { Environmental } \\
\text { factors }\end{array}$} & Competitiveness & 3 & 0.887 & Good \\
\hline & Customer pressure & 3 & 0.922 & Excellent \\
\hline & Government support & 3 & 0.916 & Excellent \\
\hline \multirow{2}{*}{$\begin{array}{l}\text { Managerial } \\
\text { factors }\end{array}$} & Top management support & 3 & 0.926 & Excellent \\
\hline & Managers' IT knowledge & 3 & 0.908 & Excellent \\
\hline
\end{tabular}

Table 2. Cronbach's alpha reliability analysis

\subsection{Discriminant Validity Assessment}

Validity refers to whether the items of the scale correctly measure the relevant instrument without additional features. Although the constructs used in this study are adopted from previous studies, the translation process of the questionnaire from its original language, the difference in research contexts, and the purpose of generalizing findings for this study require a validity analysis. In this regard, the exploratory factor analysis (EFA) with the principal axis factoring extraction method and the Promax rotation method were used. First, the sample size is 172 that satisfies the minimum case to the variable ratio of 5:1. This supports the appropriateness to run EFA (Hair et al. 2010). Second, the Kaiser-Meyer-Olkin (KMO) test and Bartlett's test of sphericity (BTOS) are used to test the factorability of the data. The data are factorable if the KMO is between 0.5 and 1 , and the BTOS is significant with the value below 0.05 (Hair et al. 2010). Third, the numbers of extracted factors are fixed for each dimension as proposed in the conceptual model so that they can achieve the acceptable eigenvalues from 0.7 (Field 2013). Finally, the minimum factor loading to allocate an item to a factor is set at 0.45 as the suggestion of Hair et al. (2010) for the sample size of 172.

Table 3 presents the results of EFA for the technological dimension. 18 items were retained from 23 initial items that were extracted into five factors. The KMO value is 0.875 . The minimum eigenvalue is 0.831 that meets the rule of Field (2013). The total of explained variance is $76.467 \%$. These offer strong evidence for the validity of the technological factors. 


\begin{tabular}{|c|c|c|c|c|c|c|}
\hline Items & Item details & F1 & F2 & F3 & F4 & F5 \\
\hline BEN4 & Growth of revenue & .830 & & & & \\
\hline BEN3 & Increase in market share & .742 & & & & \\
\hline BEN2 & Simplification of the operating procedures & .741 & & & & \\
\hline $\mathrm{BEN}_{5}$ & Creation of marketing channels & .728 & & & & \\
\hline BEN1 & Operating costs savings & .667 & & & & \\
\hline SEC2 & Availability of industry security standards for m-commerce & & .918 & & & \\
\hline CPL2 & Availability of industry standards for m-commerce applications & & .768 & & & \\
\hline$\overline{\mathrm{SEC} 1}$ & Company's awareness of the security of m-commerce & & .762 & & & \\
\hline$\overline{\mathrm{SEC} 3}$ & Availability of laws and regulations for m-commerce & & .710 & & & \\
\hline CPL3 & Presence of experience to use m-commerce applications & & .635 & & & \\
\hline CST2 & Training cost requirements & & & .848 & & \\
\hline $\mathrm{CST}_{3}$ & Maintenance cost requirements & & & .824 & & \\
\hline CST1 & Infrastructure cost requirements & & & .823 & & \\
\hline CPA1 & Alignment with the internal ICT infrastructure & & & & .921 & \\
\hline CPA2 & Integration with current business processes & & & & .762 & \\
\hline CPA3 & Adaptability of existing distribution channels & & & & .531 & \\
\hline BEN7 & Improvement in competitiveness & & & & & .819 \\
\hline BEN8 & Enhancement of customer services & & & & & .627 \\
\hline & KMO (Bartlett's Test) & \multicolumn{5}{|c|}{$.875(.000)$} \\
\hline & Eigenvalues & 8.270 & 1.999 & 1.495 & 1.167 & .831 \\
\hline & Total variance explained & \multicolumn{5}{|c|}{$76.467 \%$} \\
\hline
\end{tabular}

\section{Table 3. Factor analysis results for technological factors}

Table 4 presents the results of EFA for the organizational dimension. 7 items were retained from 9 initial items that were extracted into three factors. The KMO value is 0.804 . The minimum eigenvalue is 0.732 that meets the rule of Field (2013). The total of explained variance is $88.234 \%$. These offer strong evidence for the validity of the organizational factors.

\begin{tabular}{|l|l|c|c|c|}
\hline \multicolumn{1}{|c|}{ Item details } & F1 & F2 & F3 \\
\hline EMP2 & Employees' proficiency to use IT & .972 & & \\
\hline EMP1 & Employees' understanding of m-commerce & .894 & & \\
\hline EMP3 & Employees' competence about new technologies & .879 & & \\
\hline REA1 & Financial readiness & & .953 & \\
\hline REA2 & Technological readiness & .762 & .783 \\
\hline ORI3 & Alignment between the business strategy and m-commerce & & & .779 \\
\hline ORI2 & Alignment between IT strategy and business strategy & & $.804(.000)$ \\
\hline \multicolumn{4}{|c|}{ KMO (Bartlett's Test) } & \multicolumn{2}{|c|}{ Eigenvalues } & 4.082 & 1.361 & .732 \\
\hline \multicolumn{4}{|c|}{ Total variance explained } & \multicolumn{3}{|c|}{$88.234 \%$} \\
\hline \multicolumn{4}{|c|}{} \\
\hline F1=Employees' IT Knowledge, F2=Organizational Readiness, F3=Strategic Orientation \\
\hline
\end{tabular}

Table 4. Factor analysis results for organizational factors

Table 5 presents the results of EFA for the environmental dimension. The initial 9 items were extracted into three factors. The KMO value is 0.865 . The minimum eigenvalue is 0.838 that meets the rule of Field (2013). The total of explained variance is $85.492 \%$. These offer strong evidence for the validity of the environmental factors.

\begin{tabular}{|c|c|c|c|c|}
\hline Items & Item details & F1 & F2 & F3 \\
\hline $\mathrm{GOV}_{3}$ & Availability of training and educational programs & .923 & & \\
\hline GOV2 & Financial support from the government & .905 & & \\
\hline GOV1 & Legal considerations for $\mathrm{m}$-commerce & .786 & & \\
\hline CUS2 & Customers' expectation to adopt m-commerce & & .933 & \\
\hline CUS1 & Customers' requirement to adopt m-commerce & & .841 & \\
\hline CUS3 & The need for maintaining customers' relationships & & .802 & \\
\hline CPE2 & Availability of similar products of new entrants & & & .996 \\
\hline CPE3 & Availability of substitute products & & & .700 \\
\hline CPE1 & Availability of similar products of competitors & & & .684 \\
\hline \multicolumn{2}{|c|}{ KMO (Bartlett's Test) } & \multicolumn{3}{|c|}{$.865(.000)$} \\
\hline \multirow{2}{*}{\multicolumn{2}{|c|}{$\begin{array}{rr}\text { Eigenvalues } \\
\text { Total variance explained }\end{array}$}} & 5.405 & 1.440 & .838 \\
\hline & & \multicolumn{3}{|c|}{$85.492 \%$} \\
\hline
\end{tabular}

Table 5. Factor analysis results for environmental factors 
Table 6 presents the results of EFA for the managerial dimension. 5 items were retained from 6 initial items that were extracted into two factors. The KMO value is 0.710 . The minimum eigenvalue is 1.223 that meets the rule of Field (2013). The total of explained variance is $90.894 \%$. These offer strong evidence for the validity of the managerial factors.

\begin{tabular}{|c|c|c|c|}
\hline Items & Item details & F1 & F2 \\
\hline TMS3 & Championship of management & .929 & \\
\hline TMS1 & Managers' awareness of m-commerce & .895 & \\
\hline TMS2 & Allocation of necessary resources & .870 & \\
\hline MIT2 & Managers' proficiency to use IT & & .962 \\
\hline MIT3 & Managers' competence in new technologies & & .954 \\
\hline & KMO (Bartlett's Test) & \multicolumn{2}{|c|}{$.710(.000)$} \\
\hline & Eigenvalues & 3.322 & 1.223 \\
\hline & Total variance explained & \multicolumn{2}{|c|}{$90.894 \%$} \\
\hline
\end{tabular}

Table 6. Factor analysis results for managerial factors

\subsection{Final reliability and validity assessment}

The results from EFA support the discriminant validity of the constructs. To further assess the validity, the convergent validity of the construct should be considered by examining the average variance extracted (AVE) value for each latent construct. Furthermore, an examination of internal consistency for retained items resulting from EFA is required to ensure their reliability. As a result, Cronbach's alpha and composite reliability were applied to have a better reliability assessment for the constructs (Ifinedo 2011). Table 7 presents a summary of AVE, Cronbach's alpha and composite reliability of 13 retained constructs. The AVE values of all the constructs are greater than the suggested threshold of 0.5. This means that they are acceptable and adequate for convergent validity (Fornell and Larcker 1981). Additionally, the Cronbach's alpha and composite reliability exceed the minimum recommended a cut-off of 0.6 and 0.65 respectively (Geyskens et al. 1996), indicating the adequate reliability of the constructs.

\begin{tabular}{|l|l|c|c|c|c|}
\hline Dimensions & \multicolumn{1}{|c|}{ Constructs } & $\begin{array}{c}\text { No. of } \\
\text { items }\end{array}$ & AVE & $\begin{array}{c}\text { Cronbach's } \\
\text { Alpha }\end{array}$ & $\begin{array}{c}\text { Composite } \\
\text { Reliability }\end{array}$ \\
\hline \multirow{5}{*}{ Technology } & Perceived Direct Benefits & 5 & .553 & .879 & .898 \\
\cline { 2 - 6 } & Perceived Security & 5 & .584 & .887 & .888 \\
\cline { 2 - 6 } & Perceived Cost & 3 & .692 & .891 & .813 \\
\cline { 2 - 6 } & Perceived Compatibility & 3 & .570 & .842 & .812 \\
\cline { 2 - 6 } & Perceived Indirect Benefits & 2 & .532 & .878 & .776 \\
\hline \multirow{3}{*}{ Organization } & Employees' IT Knowledge & 3 & .839 & .945 & .780 \\
\cline { 2 - 6 } & Organizational Readiness & 2 & .744 & .857 & .717 \\
\cline { 2 - 6 } & Strategic Orientation & 2 & .610 & .780 & .766 \\
\hline \multirow{3}{*}{ Management } & Competitive Pressure & 3 & .763 & .916 & .793 \\
\cline { 2 - 6 } & Customer Pressure & 3 & .740 & .922 & .799 \\
\cline { 2 - 6 } & Government Support & 3 & .650 & .887 & .797 \\
\cline { 2 - 6 } & Top Management Support & 3 & .807 & .926 & .787 \\
\cline { 2 - 6 } & Managers' IT Knowledge & 2 & .918 & .957 & .685 \\
\hline
\end{tabular}

Table 7. AVE, Cronbach's alpha and Composite reliability for retained constructs

\section{Conclusion}

The benefits of m-commerce for businesses lead to its wide adoption in the world. The literature review indicates a huge difference in the adoption of m-commerce between the developed country and the developing country. While $\mathrm{m}$-commerce has a high level of adoption in developed countries (Mbogo, 2010), it has not been fully utilized by SMEs in developing countries (Nafea and Younas 2014). This shows that an investigation of the critical determinants for organizational $\mathrm{m}$-commerce adoption is significant for the successful adoption of m-commerce in SMEs in developing countries.

This study develops a conceptual framework for examining the critical determinants for m-commerce adoption in Vietnamese SMEs. The proposed framework is grounded from the TOE framework and the DOI theory, conceptualizing four dimensions including the technological context, the organizational context, the environmental context, and the managerial context. 
The measurement instrument for the variables in the conceptual model was preliminarily tested for its reliability and validity with the empirical data collected from the online survey of the managers of 172 SMEs in Vietnam. The study confirms the extraction of thirteen variables including perceived direct benefits, perceived security, perceived cost, perceived compatibility, perceived indirect benefits, employees' IT knowledge, organizational readiness, strategic orientation, competitive pressure, customer pressure, government support, top management support, and managers' IT knowledge for investigating the adoption of $\mathrm{m}$-commerce in Vietnamese SMEs.

This preliminary study supports an in-deep investigation of the critical determinants of m-commerce adoption in Vietnamese SMEs. It, however, has some limitations. First, the data were collected from the small sample size of 172 . As a result, there needs to increase the sample size to have more robust data for significant results. Second, there needs to have more analysis such as confirmatory factor analysis to have strong support for the appropriateness of the measurement instrument and to ensure the significance of further results. Furthermore, the target population for data collection is SMEs in the case of the Vietnamese market that includes adopters and non-adopters. As a result, the differences in their perception on the critical determinants can create the bias for empirical results.

\section{References}

Al-Qirim, N. 2006. "Mobile commerce technologies penetration in small to medium-sized enterprises in New Zealand," in International Conference on Innovations in Information Technology, Dubai, United Arab Emirates, November.

Alam, S.S., Khatibi, A., Ahmad, M.I.S., and Ismail, H.B. 2008. "Factors affecting e-commerce adoption in the electronic manufacturing companies in Malaysia," International Journal of Commerce and Management (17:1/2), pp. 125-139.

Alfahl, H., Houghton, L., and Sanzogni, L. 2017. "Mobile Commerce Adoption in Saudi Organizations: A Qualitative Study," International Journal of Enterprise Information Systems (13:4), pp. 31-57.

Alfahl, H., Sanzogni, L., and Houghton, L. 2012. "Mobile commerce adoption in organizations: A literature review and future research directions," Journal of Electronic Commerce in Organizations (10:2), pp. 61-78.

Alqatan, S., Noor, N.M.M., Man, M., and Mohemad, R. 2017. "A theoretical discussion of factors affecting the acceptance of m-commerce among SMTEs by integrating TTF with TAM," International Journal of Business Information Systems (26:1), pp. 66-111.

Alrawabdeh, W. 2014. "Environmental Factors Affecting Mobile Commerce Adoption - An Exploratory Study on the Telecommunication Firms in Jordan," International Journal of Business and Social Science (5:8), pp. 151-164.

Amegbe, H., Hanu, C., and Nuwasiima, A. 2017. "Small-Scale Individual Entrepreneurs (SIEs) and the Usage of Mobile Money (M-money) and Mobile Commerce (M-commerce) in Facilitating Business Growth in Ghana," Management Science Letters (7:8), pp. 373-384.

Ayyagari, M., Beck, T., and Kunt, A.D. 2007. "Small and medium enterprises across the globe," Small Business Economics (29:4), pp. 415-434.

Baker, J. 2012, The Technology-Organization-Environment Framework, in Information Systems Theory. London: Springer.

Barry, H., and Milner, B. 2002. "SMEs and electronic commerce: A departure from the traditional prioritization of training," Journal of European Industrial Training (26:7), pp. 316-326.

Chong, A.Y.L. 2013. "Predicting m-commerce adoption determinants: A neural network approach," Expert Systems with Applications (40:2), pp. 523-530.

Creswell, J.W. 2012. Educational research: Planning, conducting, and evaluating quantitative and qualitative research. Boston: Pearson.

Depietro, R., Wiarda, E., and Fleischer, M. 1990. "The context for change: Organization, technology and environment," The Processes of Technological Innovation (199), pp. 151-175.

Doolin, B., and Ali, E.A.H. 2008. "Adoption of mobile technology in the supply chain: An exploratory cross-case analysis," International Journal of E-Business Research (4:4), pp. 1-15. 
Duan, X., Deng, H., and Corbitt, B. 2010. "An Empirical Investigation of the Critical Determinants for the Adoption of E-Market in Australian Small-and-Medium Sized Enterprises," in $21^{\text {st }}$ Australasian Conference on Information Systems, Brisbane, Australia, December.

Duan, X., Deng, H., and Corbitt, B. 2012. "Evaluating the critical determinants for adopting e-market in Australian small and medium-sized enterprises," Management Research Review (35:3), pp. 289308.

Dyer, J.H., and Singh, H. 1998. "The relational view: Cooperative strategy and sources of interorganizational competitive advantage," Academy of Management Review (23:4), pp. 66o-679.

Field, A.P. 2013. Discovering statistics using IBM SPSS statistics. London, UK: Sage.

Fornell, C., and Larcker, D.F. 1981. "Evaluating structural equation models with unobservable variables and measurement error," Journal of Marketing Research (18:1), pp. 39-50.

General Statistics Office of Vietnam 2016. "Statistical Handbook of Vietnam." http://ntapprdfso1no1.rmit.internal/el3/e34243/Downloads/Ruot\%20nien\%20giam\%20TT.pdf Retrieved 17 August, 2017.

Geyskens, I., Steenkamp, J.B.E.M., Scheer, L.K., and Kumar, N. 1996. "The effects of trust and interdependence on relationship commitment: A trans-Atlantic study," International Journal of Research in Marketing (13:4), pp. 303-317.

Grandhi, S., and Wibowo, S. 2016. "Mobile Commerce Adoption in North American Organizations: An Empirical Study of Organizational Factors," Communications of the IBIMA (2016:2016), pp. 1-17.

Hair, J.F., Black, W.C., Babin, B.J., Anderson, R.E., and Tatham, R.L. 2010. Multivariate data analysis. Upper Saddle River, NJ: Pearson Prentice Hall.

Hamdan, A.R., Yahaya, J.H., Deraman, A., and Jusoh, Y.Y. 2016. "The success factors and barriers of information technology implementation in small and medium enterprises: An empirical study in Malaysia," International Journal of Business Information Systems (21:4), pp. 477-494.

Huy, L.V., Rowe, F., Truex, D., and Huynh, M.Q. 2012. "An empirical study of determinants of ecommerce adoption in SMEs in Vietnam: An economy in transition," Journal of Global Information Management (20:3), pp. 23-54.

Ifinedo, P. 2011. "Internet/e-business technologies acceptance in Canada's SMEs: An exploratory investigation," Internet Research (21:3), pp. 255-281.

Imre, O. 2016. "Adopting Information Systems in a Small Company: A Longitudinal Study," Journal of Applied Economics \& Business Research (6:4), pp. 269-283.

Insides, B. 2011. "The development of small and medium enterprises in Vietnam." http://businessinsides.com/development-vietnam-small-medium-enterprises.html Retrieved 15 August, 2017.

Jain, M., Le, A.N.H., Lin, J.Y.C., and Cheng, J.M.S. 2011. "Exploring the factors favouring mcommerce adoption among Indian MSMEs: A TOE perspective," Tunghai Management Review (13:1), pp. 147-188.

Lippert, S.K., and Govindarajulu, C. 2006. "Technological, organizational, and environmental antecedents to web services adoption," Communications of the IIMA (6:1), pp. 146-160.

Lu, M.T., Hu, S.K., Huang, L.H., and Tzeng, G.H. 2015. "Evaluating the implementation of businessto-business m-commerce by SMEs based on a new hybrid MADM model," Management Decision (53:2), pp. 290-317.

Mallat, N., and Tuunainen, V.K. 2008. "Exploring merchant adoption of mobile payment systems: An empirical study," E-service Journal (6:2), pp. 24-57.

Martin, S.S., Catalan, B.L., and Jeronimo, M.A.R. 2012. "Factors determining firms' perceived performance of mobile commerce," Industrial Management \& Data Systems (112:6), pp. 946-963.

Mashagba, F.F.A., Mashagba, E.F.A., and Nassar, M.O. 2013. "Exploring Technological Factors Affecting the Adoption of M-Commerce in Jordan," Australian Journal of Basic and Applied Sciences (7:6), pp. 395-400. 
Mbogo, M. 2010. "The impact of mobile payments on the success and growth of micro-business: The case of M-Pesa in Kenya," Journal of Language, Technology \& Entrepreneurship in Africa (2:1), pp. 182-203.

Nafea, I., and Younas, M. 2014. "Improving the performance and reliability of mobile commerce in developing countries," in International Conference on Mobile Web and Information Systems, Barcelona, Spain, August.

Njenga, A.K., Litondo, K., and Omwansa, T. 2016. "A Theoretical Review of Mobile Commerce Success Determinants," Journal of Information Engineering and Applications (6:5), pp. 13-23.

OEDC 2004. "OECD Information Technology Outlook." https://www.oecd.org/sti/ieconomy/37620123.pdf Retrieved 16 August, 2017.

Oliveira, T., and Martins, M.F. 2010. "Understanding e-business adoption across industries in European countries," Industrial Management \& Data Systems (110:9), pp. 1337-1354.

Otieno, E.O., and Kahonge, A.M. 2014. "Adoption of Mobile Payments in Kenyan Businesses: A Case Study of Small and Medium Enterprises (SME) in Kenya," International Journal of Computer Applications (107:7), pp. 5-12.

Picoto, W.N., Belanger, F., and Palma-dos-Reis, A. 2014. "An organizational perspective on mbusiness: Usage factors and value determination," European Journal of Information Systems (23:5), pp. 571-592.

Poon, S. 2002. "Have SMEs benefited from e-commerce?," Australasian Journal of Information Systems (10:1), pp. 66-72.

Rahman, M.M. 2013. "Barriers to M-commerce adoption in developing countries - A qualitative study among the stakeholders of Bangladesh," The International Technology Management Review (3:2), pp. 80-91.

Rogers, E.M. 2010, Diffusion of innovations. New York, USA: Simon and Schuster.

Seyal, A.H., Rahman, M.N.A., and Mohammad, H.A.Y. 2007. "A quantitative analysis of factors contributing electronic data interchange adoption among Bruneian SMEs: A pilot study," Business Process Management Journal (13:5), pp. 728-746.

Shih, Y.Y., Chen, C.Y., Wu, C.H., Huang, T., and Shiu, S.H. 2010. "Adopted Intention of Mobile Commerce from TAM Perspective: An Empirical Study of Real Estate Industry," in 2010 Portland International Center for Management of Engineering and Technology Conference, Phuket, Thailand.

Smith, A.D. 2006. "Exploring m-commerce in terms of viability, growth and challenges," International Journal of Mobile Communications (4:6), pp. 682-703.

Snowden, S., Spafford, J., Michaelides, R., and Hopkins, J. 2006. "Technology acceptance and mcommerce in an operational environment," Journal of Enterprise Information Management (19:5), pp. 525-539.

Stockdale, R., and Standing, C. 2004. "Benefits and barriers of electronic marketplace participation: An SME perspective," Journal of Enterprise Information Management (17:4), pp. 301-311.

Stoica, M., Miller, D.W., and Stotlar, D. 2005. "New technology adoption, business strategy and government involvement: The case of mobile commerce," Journal of Nonprofit \& Public Sector Marketing (13:1-2), pp. 213-232.

Tetteh, E., and Burn, J. 2001. "Global strategies for SME-business: Applying the SMALL framework," Logistics Information Management (14:1), pp. 171-180.

Vaithianathan, S. 2010. "A review of e-commerce literature on India and research agenda for the future," Electronic Commerce Research (10:1), pp. 83-97.

Varshney, U., and Vetter, R. 2004. "Mobile commerce: framework, applications and networking support," Mobile Networks and Applications (7:3), pp. 185-198.

VECITA 2017. "20\% of SMEs have been ready for electronic commerce." https://tintuc.inet.vn/chi20-doanh-nghiep-vua-va-nho-tiep-can-thuong-mai-dien-tu.html Retrieved 24 July, 2017.

Welsh, J.A., and White, J.F. 1981. "A small business is not a little big business," Harvard Business Review (59:4), pp. 18-32. 